\title{
An Overview of Sustainability of Transportation Systems: A Quality Oriented Approach
}

\author{
Ayşenur ERDIL
}

\begin{abstract}
Sustainable transportation system-structure is crucial for the population of mega countries. This system aims to provide better and more qualified alternatives of supplying specific and household requirements while decreasing the ecological and social effects of present mobility applications. The objective of this study is to investigate the risk factors of substantial transportation arrangement in the ordinary railway system and highway transportations. According to the basic issue, which is indicated in this study, the purpose of this research is to define improvements, which can support flexible transportation and control the traffic jams and properties of the proposed structure for the populations in the system. This research supports a conventional review for transportation systems in environmental conditions, pollutions, and forestlands. To address this topic, a quality-oriented implementation was applied to evaluate the failure modes and effect analysis and the significant factors were determined via Pareto Analysis to control and prevent the probable failures in the transportations systems.
\end{abstract}

Keywords: failure mode; quality; Pareto analysis; risks; sustainability; transportation

\section{INTRODUCTION}

In the light of the approach of ecological research and supervisory regulation, there are structural investigations that emphasize the requirement for symbols of advancement approaching sustainability [1]: Focused on the three dimensions' approach, a sustainability pointer can be declared as a determinable impact of environmental, economic, or social structure which is useful especially for the following differences in the system structure factors appropriate for the maintenance of household and environmental comfort.

However, sustainable improvement consists of three basic scopes including ecology, economy, and social balance, which are the significant issues related to economic activity through environmental scope and subjects. These subjects are generally of a negative area (reducing the consumption of sources, climate change and ecological pollution), generating sustainable improvement to present a risk scheduling classification of activities and it is like a development which can be a framework of advantage. Sustainable improvement is validated as a managing business password of implementation. This structure has to be converted into applications of companies. Different theories (Industrial Environment) and equipment, (Life Cycle Evaluation) support this conversion $[1,2]$.

The structure of sustainable development is to guarantee fair and honest occasions concerning improvement advantages for recent and next generations by estimation of the mutual actions among social, environmental ecological and economic subjects in an interconnected framework [2].

Sustainability evaluation is a complex issue. This subject requires information and data for various fields and multi-disciplinary assessment from different sources, the participation of researchers. In this context, some parts of studies have purposed sustainability evaluation structures to measure the performance of sustainability. These studies have applied sustainability criteria. For instance, Ugwu et al. [3] improved a model named as sustainability estimation in substructure projects to execute sustainability evaluation at the study level. Koo and Ariaratnam [4] presented a model for clearly evaluating the sustainability of underground infrastructure. However, these studies have some shortcomings considering the uncertainty situations in the process and stages of sustainability evaluation. Devuyst [5] stated sustainability evaluation as a means to support decision-makers and strategy-practitioners in order to determine what services they might get and might not get in an initiative to make society more sustainable. There are different methods to evaluate the sustainability and dimensions of it. Specifying the indicator perception can be provided in terms of consistency over time and utility in the decision-making steps and evaluation $[1,5]$.

Sustainable system supports some significant issues. These factors provide decreasing resource components, inputs, disposal outputs and minimizing the failure effects of transportation in the public dimension. This situation depends on the technologies, which are most convenient to the varieties of service requirements. It is of vital importance to daily routines such as basic services, shopping, and entertainment. This is a healthier mode of supplying among organisations, which improve the health of households providing them with more facilities such as walking for a few minutes or a bicycle trip $[6,9,10]$.

Ethical and technological impacts such as developed fuel efficiency, decreased emissions or systems, which control traffic movement on intensive highways, are crucial; however, they are not the essence of sustainable transportation. Sustainable transportation aims at lowering financial costs to the association and individual through decreasing reliance upon automobiles as the basic mode of individual mobility. Currently, it occurs that the world is at the start level of a significant change, or 'paradigm shift', in the parts of these stages in which transportation is considered, organized, financed and performed [7, 8].

Transformation is a different issue from automobile oriented provision that focuses on system growth. People employed in the transportation sector have background experience in planning, engineering, strategic management or they work in order to maintain their experiences of applications and to brainstorm about scheduling with the transportation system $[9,12,13]$.

Sustainable transportation has appeared as an important issue in recent times, however influences of sustainability are as early as mobility itself. This paper aims to define developments, which might corroborate 
modifiable transportation modes. The study also contains traffic problems and attributes of suggested framework for households for the system. As a contribution to the goal of this topic, it presents the outlines of the vital subjects and issues related to sustainable transportation (ST) too. The objective of the study is to focus especially on transportation structure and dimensions of sustainable transportation systems. It also presents a perspective on how automobile-dependent cities affect completely different transportation types-modes. A detailed review and discussion of the dimensions of sustainability for transportation construction and sustainable transportation is presented in the scope of this paper.

\section{SUSTAINABLE TRANSPORTATION}

Business as Ever (BAE) in transportation has claimed that the roads have been built and expanded in order to reduce traffic congestion. Numerous distinctions between traditional perceptions of Transportation, Business as ever (BAE) and sustainable transportation structure (STS) are represented as below [13-15, 17]:

- STS about loads of transportation and the counter productivity of traditional highway-centred planning as pollution rose and the harmful influences of highway extension on cities raised a lot of interest.

- Decreasing the traffic in metropolitan-cities through traffic calming and pedestrianization had many benefits for mobility and the environment, including reductions in vehicular traffic and traffic-related injuries, especially those of pedestrians and bicyclists and increases in the number of households walking, cycling and applying public transportation.

The evolution of sustainability consciousness, particularly according to the report of Brundthland Commission [11] on sustainable improvement provides the requirements of households. Thus, sustainability paradigm is very important for the transportation system too.

Sustainable transportation (ST) contains these modes. The concepts of the modes of ST are noted as below [10, 12-14]:

a) walking: involving walking reinforcement and mobility reinforcement appliances such as wheelchairs

b) bicycling: involving three-wheeled modifications

c) public transportation or transit - involving buses, rail modes, shuttle services, taxis and jitneys

d) PMVs (personal motor vehicles) - involving automobiles, two-wheelers, vans and light trucks.

Sustainable transportation structure (STS) stresses that sustainability according to the passenger transportations should $[8,15,16]$ :

- include essential access and mobility requirement with methods that do not reduce the environment impacts

not decrease the source base on which it is vulnerable

- present diversified economic and ecological destinations

- maximize proficiency in total resource usage

- develop or sustain an approach for products and services

- provide and increase the degree of liveability and qualities of urban scopes.
Differences between Sustainable Transportation System and Business as ever (BAE) are ordered with important aspects as below [17]: faster),

-highlighting quality and mobility structure (more,

-generally, some necessaries for good connections between models,

-highlighting one mode-variety (un-modality, auto mobility),

-planning and building by focusing on predictions of likely demands (forecast and supply),

-providing to expand alternative roads - subways to travel demand, and also modifying much more social and environmental expenses and costs.

Sustainable Transportation Structure includes some significant factors. These are listed as below [8, 17]:

- highlights relative majority (multi - modal varieties)

- integrates all costs including planning and provision

- investigates to interrupt, bottlenecks of the roads and invert harmful

- $\quad$ provides transportation or mobility demands

- $\quad$ highlights interconnections (inter-modality)

- functions backwards from preferred vision to planning and provision (deliberate and decide)

- provides hypermobility - this structure relates the mobility of people, freight, and the travel distances produced by such mobility are demonstrated

- $\quad$ highlights approachability and quality level.

Two important themes about modes of ST that support the evaluation of Sustainable Transportation Structure are listed below [14]:

1) Multi-modal: the capacity to choose between various modes for a journey. Someone could go on foot, by bicycle, or any combination of these types.

2) Intermodal: the capacity to provide connections between modes, such as montaging a bicycle on a bus or transmitting between a land mode and a ferry or airport. The advantage of intermodal transmissions can be of great value to the households-population using public types. Intermodal is also a concept that is broadly defined in freight to indicate transfers between trucks and trains.

These two terms present travel-commuting alternatives or support people to connect modes for more involved travel-commuting to decrease the requirement for auto mobility.

Sustainable improvement of traffic and states, consolidation of transport types and revitalization of subway traffic have given way to the construction of many more bus stations and terminals over the previous decades. These types of multi-modal traffic intersections, focused on advanced perceptions and perfectly connected in urban matrices are generating new central positions of location development $[17,18]$.

STS is a vital structure that permits the basis access requirements of individuals and associations to provide safety for the sake of society and maintains ecosystem health. This structure is low-price, performs efficiently, suggests selection of transport mode and provides 
vivacious economy. And also ST restricts emissions and disposal within the ability of earth to assimilate them, maximizes consumption of renewable resources to the level of sustainable production, recycles and reuses components of ST $[10,19]$.

\section{PROBLEMS COMBINED WITH MOTORCAR DEPENDENCY}

The requirement to primary capital goods in transit, walking and cycling in a partial way is to accomplish many decades of shortcomings. Regarding this issue, the following perceptions can be defined as below $[8,13]$ :

- The requirement for transportation systems to be provided with valuable opportunities over private traffic, particularly through dedicated rights of road and much more traffic light privilege.
- The fundamental importance of the public dimension and its impact on non-motorized flexibility and the social condition of the city. The responsibility of households should be maintained and regenerated in the cities to provide a liveable, safer and interrelated city.

- Developing the alternative roads in which population communicates with municipality, government and preparation parts.

Many significant factors and dimensions of sustainability that shape ST (Sustainable Transportation) are classified with culture and social organization-social equity issues, economics and environmental concerns. These classified problems associated with transportation are listed in Tab. $1[16,20,21]$.

Table 1 Issues integrated with transportation [16, 20, 21, adapted by author]

\begin{tabular}{|c|c|c|}
\hline Enviromental Problems & Economic Problems & Social Problems \\
\hline Oil exposure & Congestion cost & Road Range \\
\hline Photochemeical smog & $\begin{array}{l}\text { High urban infrastructure costs for } \\
\text { sewers, water mains, roads etc. }\end{array}$ & Loss of community in neighbourhoods \\
\hline Urban sprawl & Loss of productive rural land & Loss of public safety \\
\hline Acid Rain & Poor transit cost recovery & Isolation in remote suburbs with few \\
\hline $\begin{array}{l}\text { High greenhouse gasses- } \\
\text { global warning }\end{array}$ & Loss of urban land to pavement & $\begin{array}{l}\text { Access problems for those without cars } \\
\text { or access to cars and those with disabilities }\end{array}$ \\
\hline $\begin{array}{l}\text { Greater storm water runoff } \\
\text { problems }\end{array}$ & $\begin{array}{l}\text { High proportion of city wealth spent } \\
\text { on passenger transportation }\end{array}$ & Loss of stress Life \\
\hline $\begin{array}{l}\text { Traffic problems, noise, } \\
\text { neighbourhood severance, } \\
\text { physical danger }\end{array}$ & $\begin{array}{l}\text { Economic and human costs of } \\
\text { transportation accident trauma and } \\
\text { death }\end{array}$ & $\begin{array}{l}\text { Anti-social behavior due to boredom in car- } \\
\text { dependent suburbs. }\end{array}$ \\
\hline Decimated transit systems & $\begin{array}{l}\text { Public health costs from growing } \\
\text { obesity due to sedentary auto } \\
\text { lifestyles. }\end{array}$ & $\begin{array}{l}\text { Physical and mental health problems related to } \\
\text { lack of physical activity in solated suburbs. }\end{array}$ \\
\hline
\end{tabular}

The harmful impacts of automobiles can have crucial effects on environment and public health. This is a significant proportion for social problems and relation to capacity of population to provide the demands of transportation. The layout-form of transportation and urban location usage integrated with high levels of automobile dependence cause a mass of environmental, economic and social issues for the sustainability of locations as in table 1[23]. Some issues are associated with multiple groups; however, some issues are located in one group. For instance, the issue about auto-dependence is a sub-title under transit systems and it has economic and social results, but presented under environmental issues. Table 1 supports a detailed overview of this range of problems with some chosen assessment. These issues can be rearranged by households of most physical situations and ages in the method of experience or specialist vehicle. Verification specifies that walking habit as an activity reduces depression, diabetes, cancer, heart disease etc. $[13,19]$. This is summarized as below $[14,16,19]$.

- The major undesired properties of auto-dependent environment pose some problems such as traffic noise, deterioration of the public responsibility and considerable decrease of the neighbourhood relation.
- Traffic noise penetrates into all parts of life from invasion into dwellings and work life of people to the inefficiency to communicate in public.

- The public region has difficulty as streets have been invaded by parking cars, the equipment of autodependency such as visual interference with auto-scale advertising indications.

- The requirement to assign a priority to investment in transit, walking and cycling in a prejudiced way to challenge many decades of ignorance.

- The requirement for transit systems to be presented with particular advantages over confidential traffic, particularly through much more significant rights of roads and many more traffic lights priority.

- The core significance of the public domain and its impact on non-motorized mobility and the social interaction in the city. The public domain should be preserved and reconstructed in all metropolitan and all cities to provide a liveable, safe, connected and peaceful metropolitan-city.

Automobile-dependent cities have much more economic influences such as congestion costs with regard to lost time and high expense of urban substructure for the additional distances that must be inspected for sewage, water and drainage systems, roads and diversity of social buildings 
such as medical centres, schools and society areas [16]. In the meanwhile, extended regions of existent urban buildings remain under-utilized according to the demographic replacements and are poor for revitalisation along with better movement and higher density of population. This is a significant dimension of sustainability and it has many more economic costs with regard to road incidents, accidents, and deaths, physical injury of accidents in cities.

Automobile-dependent cities have high consumption levels of private transportation energy sources. Because of this issue, automobile cities release high levels of greenhouse gases and emissions such as carbon monoxide, nitrogen oxides and hydrocarbons, which cause the appearance of photochemical smog. Automobile-dependent cities suffer from the loss of productive land or natural region due to urban extension [14]. The covering of extended region of urban location with pavement for roads, the building of comprehensive low-density accommodation areas generate enormous amounts of water runoff which can affect flooding of contaminated water from the brake and oil remains-clay forming on the pavement $[14,16]$.

\section{APPROPRIATE INFRASTRUCTURE AND ENVIRONMENTAL ASSESSMENTS}

Economic improvement, expenditure strategies, proposed costs and advantages, profits and tariffs can be reconsidered and analysed. Environmental influence evaluation, and the province of transportation vehicles are modified to pedestrians.

The energy consumption for transportation is decreased by using bicycles. In addition, it supports the summarized subjects as below $[13,15,16]$ :

- decreases the traffic jams-congestion and highway position.

- $\quad$ supports to decrease noise and air pollution, and vehicle diesel oil consumption by slowing, minimizing and smoothing traffic flow.

- decreases the barrier impacts of vehicular traffic on pedestrians, and cycle movements.

- develops local economic activity by creating a greener and better environment when compared to more autobased environments.

- decreases the traffic congestion and highway position.

- Walking is a healthy activity for the population. This impact of transportation is of the essence for sustainable and robust transportation.

- Walking, riding a bike and transportation from one place to another could be the fundamental structure of traveller transportation as they have existed in settled periods.

The threat and harm posed by climate change and the influence of urban special structure have been integrated to demonstrate the effect of climate change on land use and transportation influences with transit-oriented improvement to carry out land-use planning structure. Transportation expenses by populations and individuals: Private automobiles are uneconomic, costly $[13,15]$.
The fundamental dimensions of freight transportation consist of rail and marine shipping. These types of transportation support the reduction of energy consumption and provide the particular extent of surface effective modes of freight location $[12,14,15]$.

\section{POTENTIAL RISKS ASSESSMENT FOR SUSTAINABILITY VIA FAILURE MODES EFFECTS ANALYSIS \\ 5.1 Evaluation of Potential Risks}

Failure Modes Effects Analysis (FMEA) is a quality control method which is applied during the development of products and procedures to define, investigate and remove the occasions of failure while decreasing the impacts of failures or mistakes situations that could expand [20, 23].

Paparella [20] declares that FMEA is a practical method for risk evaluation, detection, and failure prevention. RPNs (Risk priority numbers) for FMEA methodology is applied as risk impacts for mistakes.

FMEA has an extensive usage scope for the evaluation of the potential risks of the systems. This analysis structure helps preventing the failures by considering the convenient risks. This method can be applied throughout the design period of the layout-plan and in application and montage phases. Design step is more convenient because the reduction of the failures might be more effective due to the reduction of the cost of the sources in the design stage [29, $32,33]$.

\subsection{Value Analysis}

Value Analysis has an important influence and it is based on a scientific way to improve the product and service according to the expectation of the customer, relying on the expenditure of the product to present the desired criteria according to the monetary value of resources. Value Analysis is applied in order to define the possible influences of causes [27]. According to the value analysis, the flow diagram for the planned dimensions of the impressed systems and sub-components is demonstrated in Fig. 1. According to the diagram, design verifications of all affected systems and sub-components would be observed in detail to understand if there were any other design and process changes that may have intended the problems and failures.

A fishbone diagram is a picture composes of lines and symbols designed to represent a meaningful relationship between an effect and its causes. It was developed by Dr. Kaoru Ishikawa in 1943 and is sometimes referred to as an Ishikawa diagram or a fishbone diagram of its shape. This diagram is used to investigate either a bad effect and to take action to correct the causes or a good effect and to learn these causes that are responsible. For every effect, there are likely to be numerous reasons [36]. All systems and components, as well as the quality of design and production processes, are shown within the fish bone diagram given in Fig. 2. In the fishbone diagram, the most important item is the process components of the sustainable transportation system. Therefore, the process is absolutely examined. 


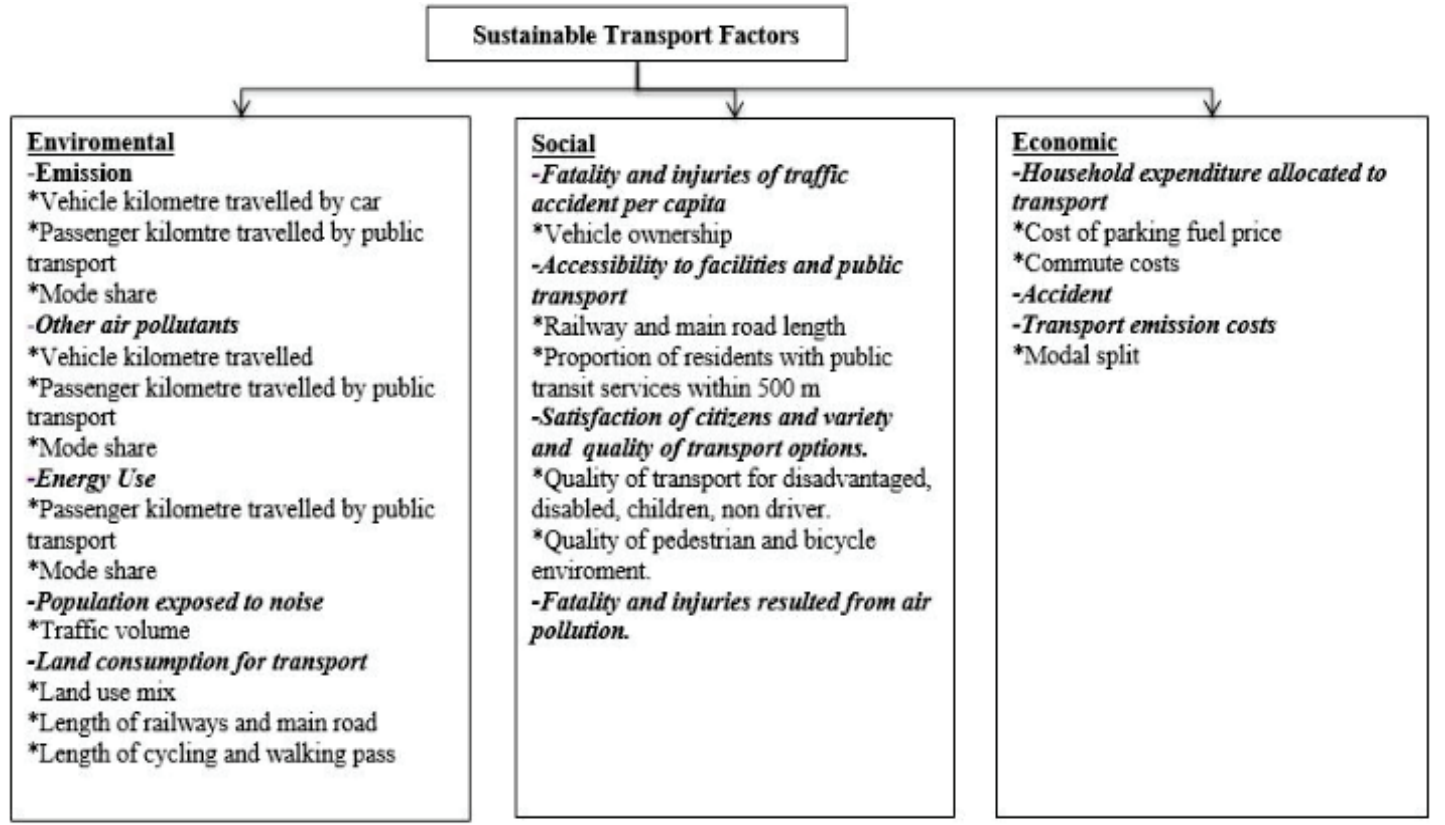

Figure 1 Sustainable transport indicators-problems [4, 9-14, 24 adapted by author]

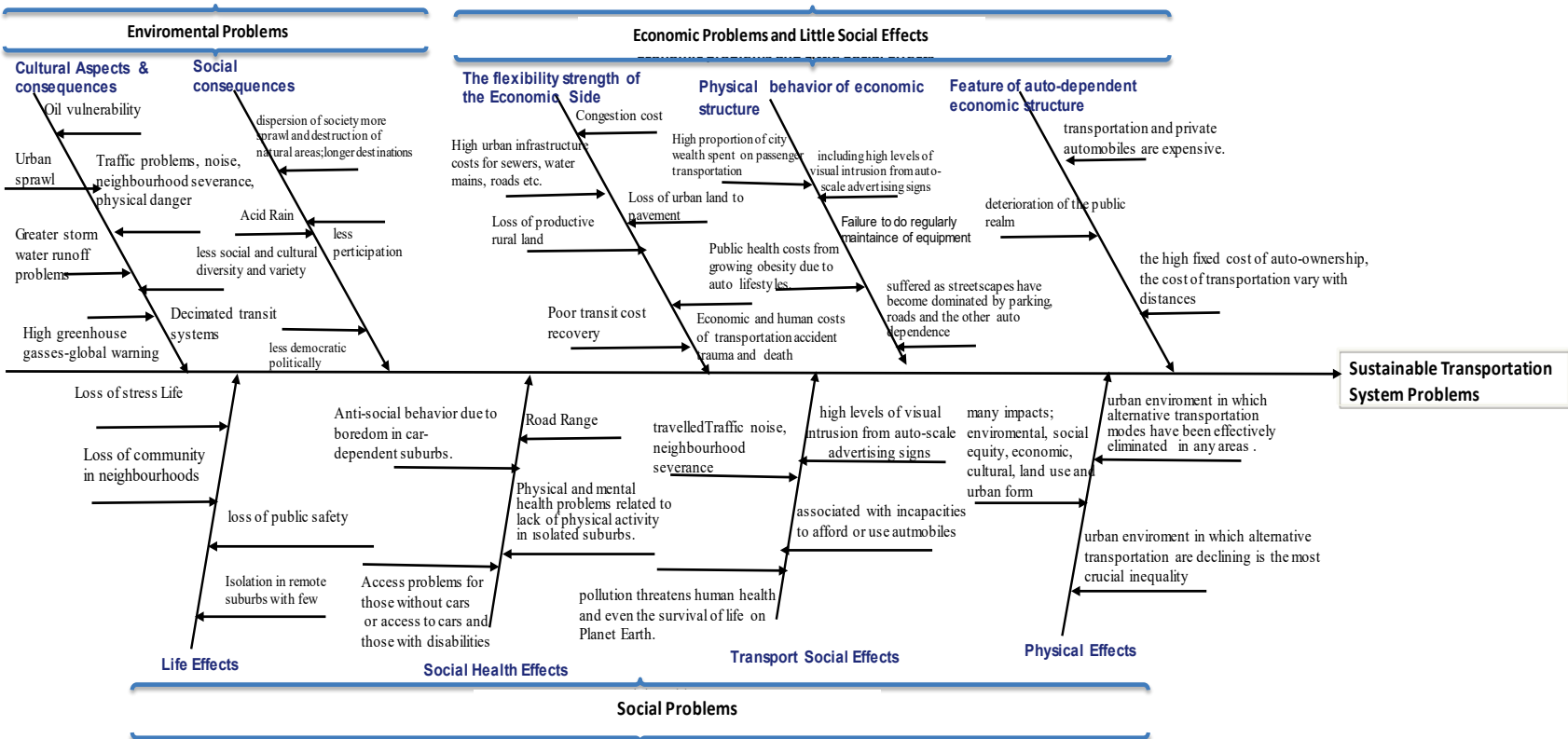

Figure 2 Fishbone diagram to detect the reasons (failures) for sustainable transportation system problems

\section{FAILURE MODES EFFECTS ANALYSIS}

Failure Modes and Effect Analysis is a methodology to determine potential reliability subjects in the improvement cycle where it is basic to take facilities to overcome these subjects, thereby to support reliability through design. The early and dependable use of FMEAs in the design process provides an engineer to design out failures and produce reliable, safe products. FMEAs also include historical information to use for development of future products. FMEA is developed to provide the quality and reliability of the design. FMEA evaluations provide several advantages. These advantages involve these items $[29,32]$ :

- develop products or process reliability and quality

- provide satisfaction of the customer

- early detection, specification, and prevention potential of product risks or failure modes of process steps
- prioritize deficiencies and failures of product or process steps

- obtain knowledge of engineering scope or situation of the organization

- observe and highlight problem prevention

- describe and archive risk and actions taken to reduce risk

- discover the potential failures modes, their effects and similarities for all products/processes

- reduce the product or project development period and cost.

FMEA risk method is applied to observe the failures or defects in the implemented studies, projects before they cause a hazardous situation, and to define and control the priorities in reforming the failure issues and to eliminate the potential failures before they occur [6, 23, 30-32]. 
Risk Evaluation of the process is achieved by FMEA. Application of the FMEA includes breaking down the stages of procedure into individual points: potential failure modes (for instance causes of congestion of traffic), severity score, probability (for instance occurrence) score, harmful score and detectability. Thus, the experts can investigate for key drivers and significant issues in all process focusing on the previous observation [25, 26]. FMEA enables us to detect and evaluate the hazards and accidents in advance. However, Failure Mode Effect Analysis (FMEA) has a wide range of usage field, it is also a strong analysis technique towards preventing the failures by estimating the relevant risks [28, 32, 33].

Occurrence trends and results of purposes of failures are monitored and noted from all observations in the system. The researcher of this methodology prioritizes the purposes due to how critical importance for the consequences (for instance severity impact); how frequently the causes exist (for instance probability impact) and how easily the purposes can be detected. [29, 32].

The advantages of the FMEA are given like that it is to develop the quality level of products, services, dependability, and safety of the product or services, to provide the customer satisfaction, to decrease the product or service improvement span time and expenditure, to determine and investigate the priorities in design or process improvement facilities [29, 32, 34]. 34, 35]

The advantages of the system are given as below [31,

- It provides developing the quality, reliability, and safety of the product or project.

- It supports providing and increasing the customer satisfaction.

- It provides decreasing the product or system development period, span and expenditure.

- It aims to ascertain the priorities in design or process development activities.

- It supplies investigating the all potential failures modes, their effects, and similarities for all products/processes.

- It provides the analysis of the design needs and design alternatives.

- It supports the definition of potential, critical and important characteristics.

- It tries to supply the evaluation of new products or research steps.

- The target of this method sustains a significant brainstorming for failure prevention.

- It promotes enhancing and achieving the description of preventive actions.

- It helps to specify and monitor the risk reducing facilities.

The priority of a failure mode is regulated owing to the risk priority number $(R P N)$, which is specified as the product/service of the occurrence $(\mathrm{Or})$, severity $(\mathrm{Sr})$ and detection $(D r)$ of the error/failure. Those potential causes, with high $R P N$ values are selected for the corrective action to reduce the risk of failure occurrence. Attention is also given to those parts of a system, where failure would produce adverse customer reaction and loss of company image. Risk priority numbers $(R P N)$ for FMEA (Eq. (1)) is calculated by multiplying the Occurrence $(\mathrm{Or})$, Severity $(S r)$, and Detectability $(D r)$ levels $[5,16,20,25,29]$.

$R P N=O r \times S r \times D r$

These possible reasons within high $R P N$ values are level of failure occurrence. Significance-distinction is also presented to these units of a system, where error-failure could cause a contrary consumer attitude and loss of firm vision. Risk priority numbers $(R P N)$ for FMEA methodology; is considered by multiplying these dimensions. These are Occurrence $(\mathrm{Or})$, Severity $(\mathrm{Sr})$, and Detectability (Dr) levels [5, 16, 20, 29, 35].

Severity $(\mathrm{Sr})$ : Importance of the impact on consumers needs often cannot do anything about this without essentially altering the structure of system or design.

Occurrence $(\mathrm{Or})$ : Frequency with which is determined the causes of occurrence and creates failure modes.

Detection $(D r)$ : The ability of the current tracking and control method to observe before or after the occurrence of a given cause. The three dimensions $\mathrm{Or}, \mathrm{Sr}$, and $\mathrm{Dr}$ are all considered using the rankings or scores from 1 to 10 , as specified in Tab. 2 .

Table 2 The three dimensions - $\mathrm{Or}$ (Occurrence), $\mathrm{Sr}$ (Severity) and $\mathrm{Dr}$ (Detection) of System FMEA [22]

\begin{tabular}{|c|c|c|c|}
\hline Rating & Sererity of Effect & Likelihood of Occurence & Ability to Detect \\
\hline 10 & Hazardous without warning & \multirow{2}{*}{$\begin{array}{l}\text { Very high: } \\
\text { Failure is almost inevitable }\end{array}$} & Can not detect \\
\hline 9 & Hazardous with warning & & Very remote chance of detection \\
\hline 8 & Loss of Primary function & \multirow{2}{*}{$\begin{array}{c}\text { High: } \\
\text { Repeated failures }\end{array}$} & Remote chance of detection \\
\hline 7 & $\begin{array}{c}\text { Reduced primary function } \\
\text { performance }\end{array}$ & & Very low chance of detection \\
\hline 6 & Loss of secondary function & \multirow{3}{*}{$\begin{array}{c}\text { Moderate: } \\
\text { Occasional failures }\end{array}$} & Low chance of detection \\
\hline 5 & $\begin{array}{l}\text { Reduced secondary function } \\
\text { performance }\end{array}$ & & Moderate chance of detection \\
\hline 4 & $\begin{array}{l}\text { Minor defect noticed by most } \\
\text { customers }\end{array}$ & & Moderately high chance of detection \\
\hline 3 & $\begin{array}{c}\text { Minor defect noticed by some } \\
\text { customers }\end{array}$ & \multirow{2}{*}{$\begin{array}{l}\text { Low: } \\
\text { Relatively few failures }\end{array}$} & High chance of detection \\
\hline 2 & $\begin{array}{l}\text { Minor defect noticed by } \\
\text { discriminating customers }\end{array}$ & & Very high chance of detection \\
\hline 1 & No effect & Remote: Failure is unlikely & Almost certain detection \\
\hline
\end{tabular}

After calculation of RPN, the firm should guarantee that the main hazardous effects are removed, eliminated from the particularization by re-engineering. The five specific issues (effective relations) are classified as main topics. These are Concentration-Density, Difference Diversity, Footage-Distance, Objective-Destination, and Configuration-Design. Some alternative solutions are presented with FMEA Table-Appendix 1 in order of desirability.

Fig. 3 demonstrates that the values of RPN have high value before FMEA. After the Recommended Action is applied, the RPN value decreases. The Risk Priority value has low value after FMEA. Quality oriented process development is applied in this study. In the implementation, the critical risk value is chosen as $80 \%$. Pareto analysis focused on failures and risks that could happen when designing transportation-based sustainable projects and ranked according to the severity of the risk 
factors with regard to the nature of each risk factor, and calculated values of relevant percentage $\%$ are shown.

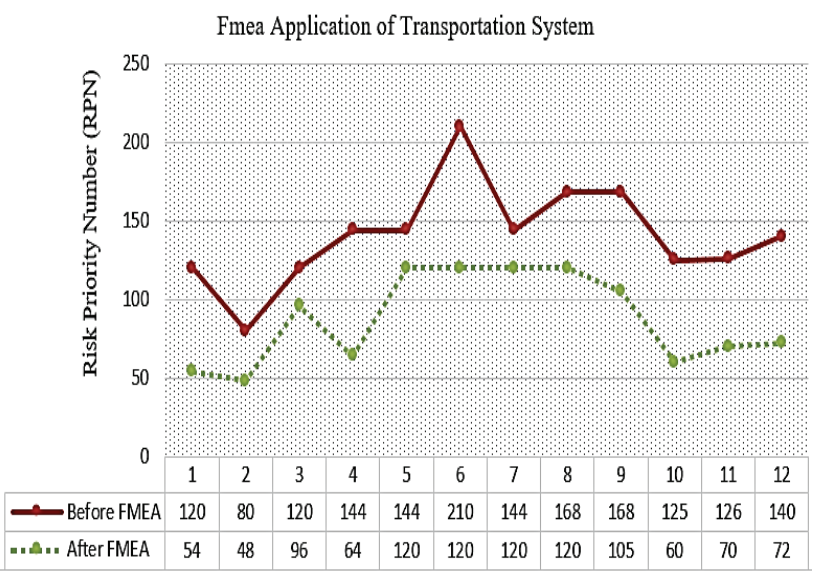

Figure 3 RPN values for before FMEA and after FMEA

This technique helps to identify the top $20 \%$ of causes that needs to be addressed to resolve the $80 \%$ of the problems.

In Tab. 3, Appendix 1 - FMEA Table and Pareto chart (Fig. 4), the encountered potential risks in the Sustainability of Transportation System are given with the advantages of failure mode effect analysis. FMEA method and risk priority calculation values are determined based on observation and previous experience. In this Tab. 3, there have been considered 12 main aspects-failures to be subjected to the control and may cause risk factor during the study. Among these 12 potential failure and risk modes, 8 of them considered as high risk and remaining 4 of them medium level risk as per the calculated risk priority values.

Table 3 Designed Pareto analysis in transportation-based sustainability engineering projects (components of high-risk error by $80 \%$ threshold value of the risks in the generated Pareto chart)

\begin{tabular}{|c|c|c|c|c|}
\hline $\begin{array}{c}\text { \# of } \\
\text { Potential } \\
\text { Failure }\end{array}$ & $\begin{array}{c}\text { Risk Priority } \\
\text { Number (RPN) }\end{array}$ & $\begin{array}{c}\text { Percentage } \\
\text { of RPN }\end{array}$ & $\begin{array}{c}\text { Cumulative } \\
\text { Percentage } \\
\text { of RPN }\end{array}$ & Risk \\
\hline 6 & 210 & 12,4334 & 12,4334 & $\begin{array}{c}\text { UnAcceptable } \\
\text { Risk }\end{array}$ \\
\hline 8 & 168 & 9,9467 & 22,3801 & $\begin{array}{c}\text { UnAcceptable } \\
\text { Risk }\end{array}$ \\
\hline 9 & 168 & 9,9467 & 32,3268 & $\begin{array}{c}\text { UnAcceptable } \\
\text { Risk }\end{array}$ \\
\hline 4 & 144 & 8,5258 & 40,8526 & $\begin{array}{c}\text { UnAcceptable } \\
\text { Risk }\end{array}$ \\
\hline 5 & 144 & 8,5258 & 49,3783 & $\begin{array}{c}\text { UnAcceptable } \\
\text { Risk }\end{array}$ \\
\hline 7 & 144 & 8,5258 & 57,9041 & $\begin{array}{c}\text { UnAcceptable } \\
\text { Risk }\end{array}$ \\
\hline 12 & 140 & 8,2889 & 66,1930 & $\begin{array}{c}\text { UnAcceptable } \\
\text { Risk }\end{array}$ \\
\hline 11 & 126 & 7,4600 & 73,6530 & $\begin{array}{c}\text { UnAcceptable } \\
\text { Risk }\end{array}$ \\
\hline 10 & 125 & 7,4008 & 81,0539 & $\begin{array}{c}\text { Medivm } \\
\text { Risk }\end{array}$ \\
\hline 1 & 120 & 7,1048 & 88,1587 & $\begin{array}{c}\text { Medivm } \\
\text { Risk }\end{array}$ \\
\hline 3 & 120 & 7,1048 & 95,2635 & $\begin{array}{c}\text { Medivm } \\
\text { Risk }\end{array}$ \\
\hline 2 & 80 & 4,7365 & 100,0000 & $\begin{array}{c}\text { Medivm } \\
\text { Risk }\end{array}$ \\
\hline
\end{tabular}

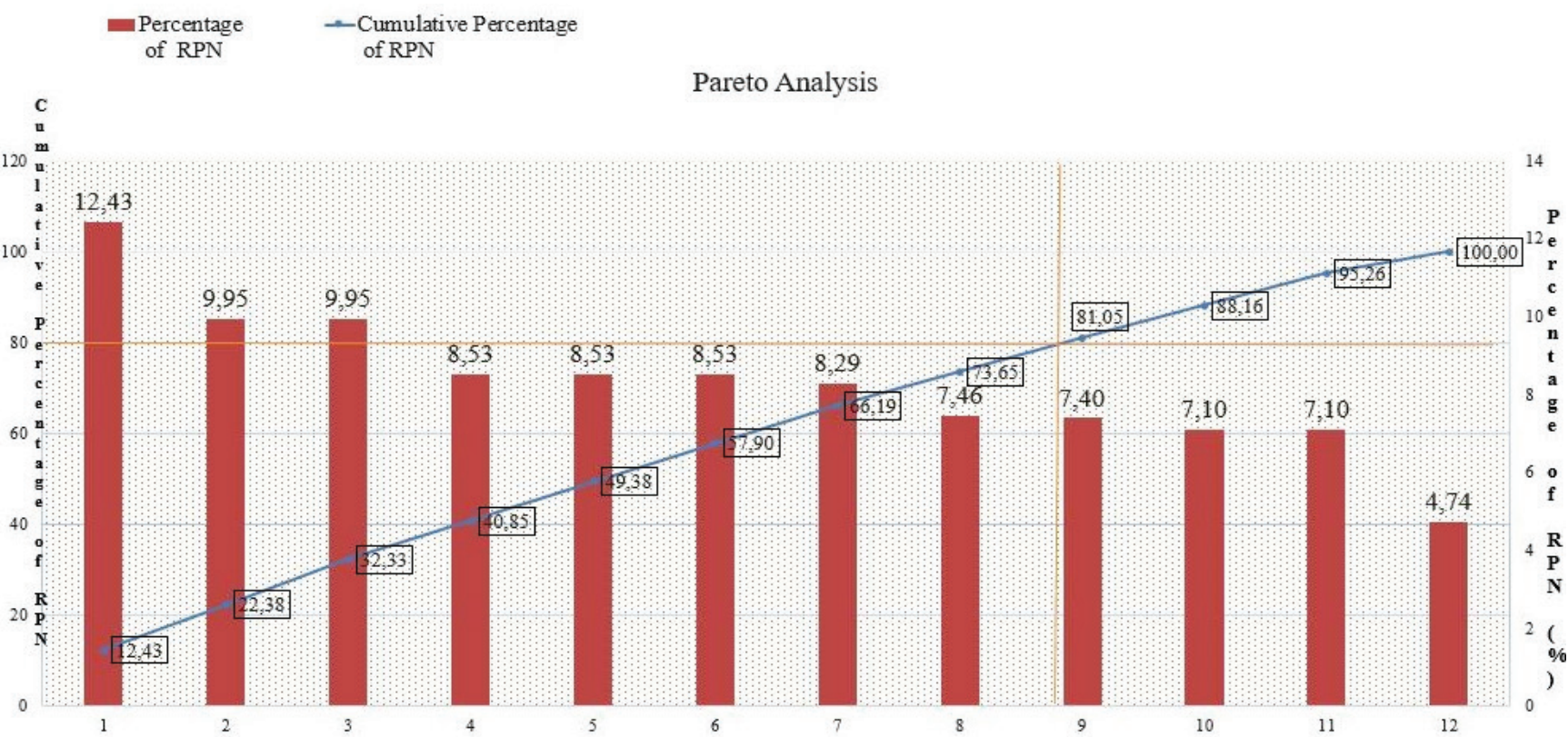

Figure 4 Pareto diagram of high-risk situations

\section{CONCLUSION}

FMEA analysis in the sustainability of transportation systems plays an important role especially during the design phase of projects in order to provide the risks to be based on the priority order of importance and for the improvement works for them to be made quickly. However, in the transportation - service studies, Risk Priority Level (RPL) values play an important role that are found for the previous analysis and evaluation of FMEA, will be a good guidance for the people of experts in their field that carry out improvement studies. Transportation
Oriented Planning model is for the integration of land use and transportation while this study focuses on the mutual relationship in climate changes and land use, risk factors and makes a correction for the pattern.

The $R P N \mathrm{~s}$ is especially declared in FMEA for the risk prioritization of failure types. The specified FMEA condition can be important for design and construction to manage the choice standards. Future studies might be oriented to the efficient examination of convenience chosen for the three factors of sustainability. Social, Economic and Environmental oriented model is for the construction of sustainable transportation system with the 
interconnection of location determination, assessment of green locations, health safety of households and quality improvement of substructure for this study. It deals with the subgroups of the problems of transportation system that FMEA is a classified decision approach and can be applied on a subjective support and evaluation. And also, this research can be extended and detailed with the shared common connection in climate changes, green friendly analysis, evaluation of risk dimensions and it can provide a development for the arrangement of transportation system in the future research area.

The suggested FMEA is not restricted to $\mathrm{Or}, \mathrm{Sr}$ and $\mathrm{Dr}$, but is relevant to some number of risk criteria. This study focuses on a major part of dimensions of sustainability. According to this, Lean Six sigma can be used and implemented to evaluate by adding different criteria of dimensions of sustainability for transportation system and to integrate with green transportation management for the next study.

\section{Acknowledgements}

We would like to thank officials of municipality and experts who shared for valuable information and discussions.

\section{REFERENCES}

[1] Kates, R. W., Clark, W. C., Correll, R., Hall, M. J., Jaeger, C. C., Lowe, I., McCarthy, J. J., Schellnhuber, H. J., Bolin, B., Dickson, N. M., Faucheux, S., Gallopin, G. C., Grübler, A., Huntley, B., Jäger, J., Jodha, N. S., Kasperson, R. E., Mabogunje, A., Matson, P., Mooney, H., Moore III, B., O'Riordan, T.; \& Svedin, U. (2001). Policy Forum: Environment and Development, Sustainability Science. Science, 292(5517), 641-642. https://www.albany.edu/ gogreen/files/documents/faculty\%20forum/Kates.pdf. (Accessed on 10.06.2015).

[2] (2012). Turkey's Sustainable Development Report: Claiming the Future Best Practice Examples on Sustainable Development, 1-82. (Accesed on 10.05.2015).

[3] Ugwu, A., Kumaraswamy, M., Wong, A., \& Ng, S. (2006). Sustainability appraisal in infrastructure projects (SUSAIP): Part 1. Development of indicators and computational methods. Automation in Construction, 15(2). 239-251. https://doi.org/10.1016/j.autcon.2005.05.006

[4] Koo, H. \& Ariaratnam, S. (2008). Application of a Sustainability Model for Assessing Water Main Replacement Options. Journal of Construction Engineering and Management, 134(8), 563-574. https://doi.org/10.1061/(ASCE)0733-9364(2008)134:8(563)

[5] Devuyst, D., Hens, L., \& Lannoy, W. D. (2001). How Green Is the City? Sustainability Assessment and the Management of Urban Environments. New York: Columbia University Press. https://doi.org/10.7312/devu11802

[6] Shaheen, S. A. \& Rodier, C. J. (2006). EasyConnect: LowSpeed Modes Linked to Transit Planning Project, Institute of Transportation Studies University of California, California Path Working Paper, 7.

http://innovativemobility.org/wp-content/uploads/2015/01/ PWP-2006-07.pdf (Accesed on 10.10.2016)

[7] (2012). A Guide for Sustainable Urban Development in the 21st Century. United Nations Department of Economic and Social Affairs (Undesa)-Sustainable Urban Transport / Manual, S., 1-18.

[8] China-Nung, L. (2012). Low Carbon Management Concept in TOD Planning. Sustainable Transportation in Systems,
Plan, Design, Build and Maintain. Processing of the $6^{\text {th }}$ Asia Public Transportation Development Conference (ASCE).

[9] Newman, P. \& Kenworthy, J. R. (1989). Cities and Automobile Dependence: A Source Book, Gower Publishing Company.

[10] Escobar, L.; Papetti, A.; Sacher, B.; Rosin, K. (2011). Sustainable Transportation, The City of Winnipeg. http://www.winnipeg.ca/interhom/CityHall/OurWinnipeg/p df/SustainableTransportation.pdf. (Accessed on 10.10.2016)

[11](1987). World Commission on Environment and Development. From One Earth to One World: An Overview. Oxford: Oxford University Press.

[12] Stringer, P. (1976). Transportation Planning for a Better Environment, Vol. 1, Plenum Press. New York and London, Springer, Plenum Press, New York.

[13] Schiller, P. L., Bruun, E., \& Kenworthy, J. (2010). An Introduction to Sustainability Transportation, Policy, Planning, and Implementation. Published by Earthscan, London, Washington, DC.

[14] Friedl， B. \& Steininger, K. (2002). Environmentally Sustainable Transport Volumes for Austria Environmentally Sustainable Transport: Definition and Long-Term Economic Impacts for Austria. Empirica, 29(2), 163-180. https://link.springer.com/article/10.1023/A:1015600911243

[15] Kenworthy, J. R. (2003). Automobile Dependence in Bangkok: An International Comparison with Implications for Planning Policies. In Whitelegg, J., and Haq, G. (editors) The Earthscan Reader on Transport Policy and Practice. Chapter 6, 61-77. Earthscan Publications, London.

[16] Newman, P. \& Kenworthy, J. (1999). Sustainability and Cities: Overcoming Automobile Dependence. Washington, D. C.: Island Press.

[17] Bertolini, L. (2000). Planning In the Borderless City. A Conceptualisation and an Application to the Case of Station Area Redevelopment. Town Planning Review, 71(4), 455475. https://doi.org/10.3828/tpr.71.4.2883q121q1671185

[18] Stevanović, K. N.; Stevanović, M. V. (2014). New directions in the design of railways stations. Građevinar, 66(8), 739747. https://doi.org/10.14256/JCE.975.2013

[19] Cervero, R. (2013). Transport Infrastructure and the Environment: Sustainable Mobility and Urbanism. University of California, Berkeley, Working Paper 03. Proceedings of the $2^{\text {nd }}$ Planocosmo International Conference / Bandung Institute of Technology, 1-22.

[20] Paparella, S. (2007). Failure mode and effects analysis: a useful tool for risk identification and injury prevention. Journal of Emergency Nursing, 33(4), 367-371. https://doi.org/10.1016/j.jen.2007.03.009

[21] Su, X., Deng, Y., Mahadevan, S., \& Bao, Q. (2012). An Improved Method for Risk Evaluation in Failure Modes and Effects Analysis of Aircraft Engine Rotor Blades. Engineering Failure Analysis, 26, 164-174. https:// doi.org/10.1016/j.engfailanal.2012.07.009

[22] FMEA Ratings. http://www.suggestkeywords.com/ Zm11YSByYXRpbmdz/. (Accessed on 10.01.2017).

[23] Sankar, N. R. \& Prabhu, B. S. (2001). Modified approach for prioritization of failures in a system failure mode and effects analysis. International Journal of Quality \& Reliability Management, 18(3), 324-335. https://doi.org/10.1108/02656710110383737

[24] Ben-Daya, M. \& Raouf, A. (1996). A revised failure mode and effects analysis model. International Journal of Quality \&Reliability Management, 13(1), 43-47. https://doi.org/10.1108/02656719610108297

[25] Bowles, J. B. (2004). An assessment of PRN prioritization in a failure modes effects and criticality analysis. Journal of the IEST, 47, 51-56. https://doi.org/10.17764/jiet.47.1.y576m26127157313 
[26] Van Leeuwen, J.F.; Nauta, de-Kaste, MJ. D.; OdekerkenRombouts, Y. M. C. F., Oldenhof, M. T., Vredenbert, M. J., \& Barends, D. M. (2009). Risk Analysis by FMEA as an Element of Analytical Validation. Journal of Pharmaceutical and Biomedical Analysis, 50(5), 1085-1087. https://doi.org/10.1016/j.jpba.2009.06.049

[27] Chuang, P. T. (2010). Incorporating disservice analysis to enhance perceived service quality. Industrial Management \& Data Systems, 110(3), 1-22. https://doi.org/10.1108/02635571011030033

[28] Luca, B. \& Frank Le, C. (2003). Urban development without more mobility by car? Lessons from Amsterdam, a multimodal urban region. Environment and Planning A, 35, 579-589. https://doi.org/10.1068/a3592

[29] Chin, K. S., Wang, Y. M., Poon, G. K. K., \& Yang J. B. (2009). Failure Mode and Effects Analysis Using a GroupBased Evidential Reasoning Approach. Computers \& Operations Research, 36, 1768-1779. https:// doi.org/10.1016/j.cor.2008.05.002

[30] Pillay, A. \& Wang, J. (2003). Modified failure mode and effects analysis using approximate reasoning. Reliability Engineering \& System Safety, 79, 69-85. https://doi.org/10.1016/S0951-8320(02)00179-5

[31] Fiorenzo, F. \& Maurizio, G. (2001). A New Approach for Evaluation of Risk Priorities of Failure Modes in FMEA. International Journal of Production Research, 39(13), 29913002. https://doi.org/10.1080/00207540110056162

[32] Liu, H.-C., Liu, L., / Liu, N. (2013). Risk Evaluation Approaches in Failure Mode and Effects Analysis: A Literature Review. Expert Systems with Applications, 40(2), 828-838. https:// doi.org/10.1016/j.eswa.2012.08.010

[33] Wang, Y.-M., Chin, K.-S., Poon, G. K. K., \& Yang, J.-B. (2009). Risk Evaluation in Failure Mode and Effects Analysis Using Fuzzy Weighted Geometric Mean - Part 1. Expert Systems with Applications, 36(2), 1195-1207. https://doi.org/10.1016/j.eswa.2007.11.028

[34] Chang, D. S. \& Sun, K. L. P. (2009). Applying DEA to enhance assessment capability of FMEA. International Journal Quality \& Reliability Management, 26(6), 629-643. https://doi.org/10.1108/02656710910966165

[35] Estorilio, C. \& Posso, R. K. (2010). The reduction of irregularities in the use of process FMEA. International Journal Quality \& Reliability Management, 27(6), 721-733. https://doi.org/10.1108/02656711011054579.

[36] Besterfield, H. D., Besterfield-Michna, C., Besterfield, H. G., \& Besterfield-Sacre, M. (1999). Total Quality Management $\left(2^{\text {nd }}\right.$ ed.). London: Prentice Hall.

\section{Contact information:}

\section{Ayşenur ERDIL}

Marmara University, Engineering Faculty

Goztepe Campus Kadıkoy

34722 - Istanbul/Turkey

aysenur.erdil@marmara.edu.tr

erdil.aysenur@gmail.com 
Appendix 1 FMEA Table of Sustainable Transportation - 1

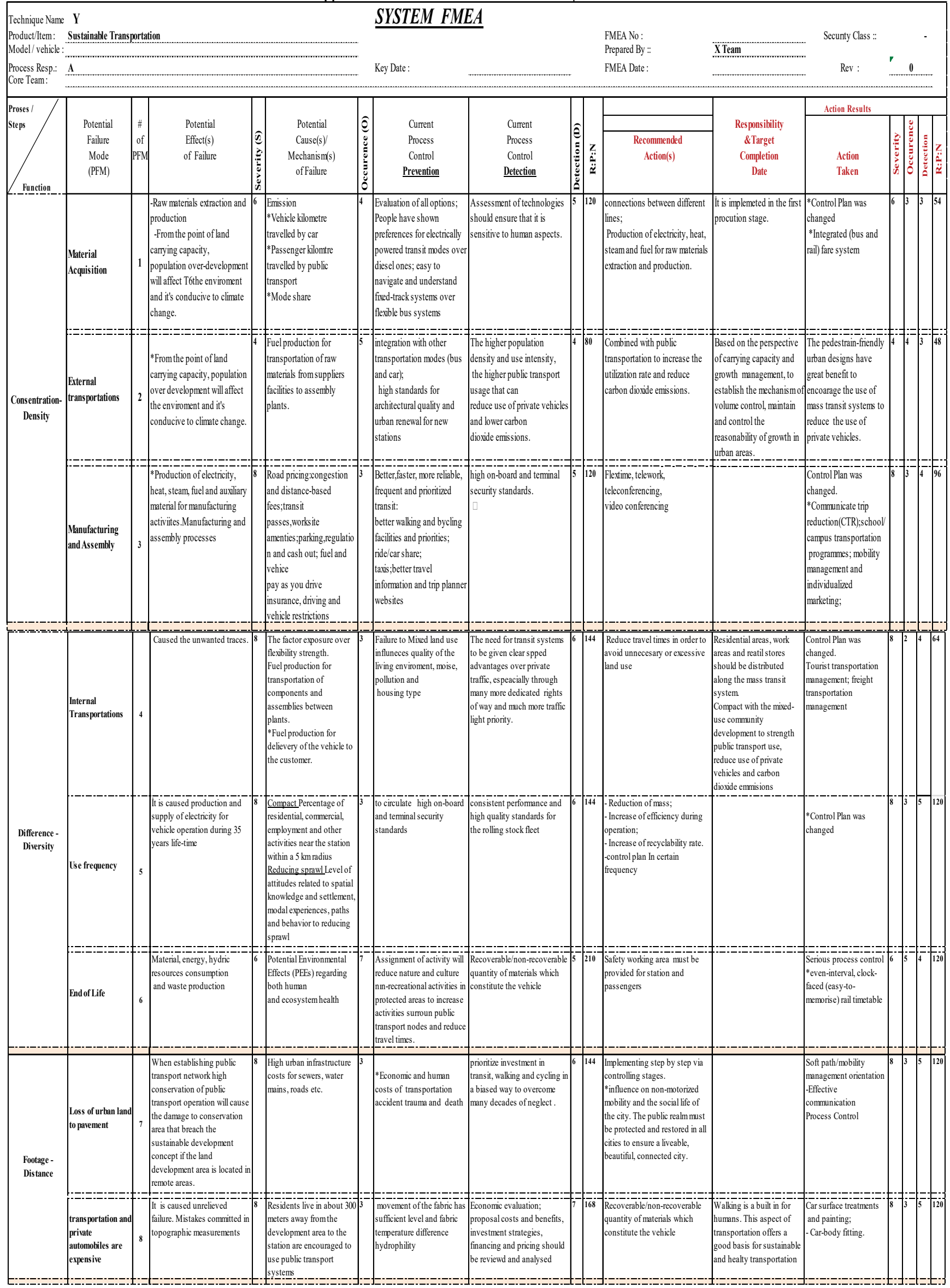




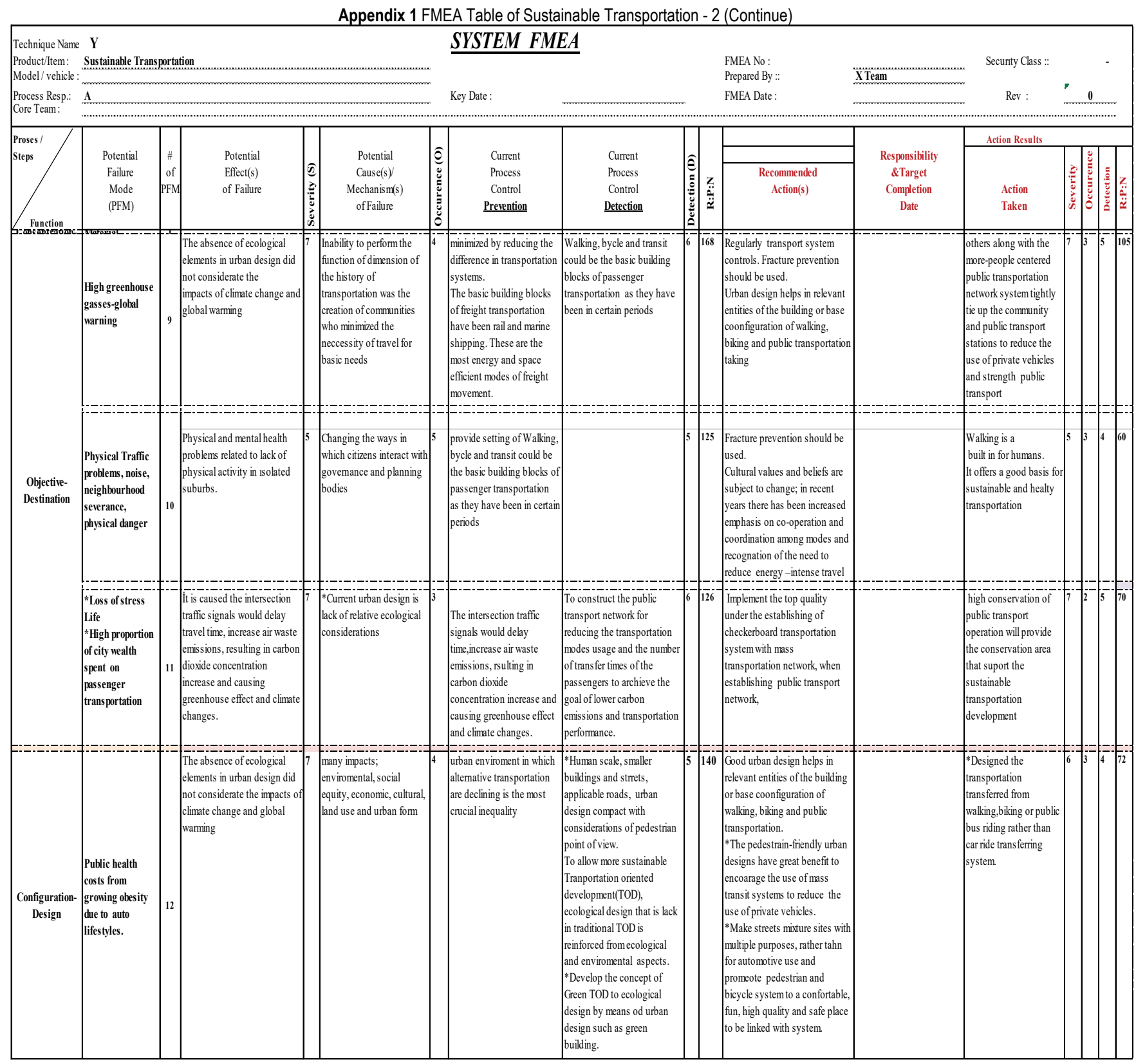

